\title{
X-Ray Absorption Study of Ti-bearing Silicate Glasses
}

\author{
D.B. Dingwell ${ }^{1}$, E. Paris $^{2}$, F. Seifert ${ }^{1}$, A. Mottana ${ }^{3}$, C. Romano ${ }^{1}$ \\ ${ }^{1}$ Bayerisches Geoinstitut, Universität Bayreuth, D-95440 Bayreuth, Germany \\ ${ }^{2}$ Dipartimento di Scienze della Terra, Universita' di Camerino, I-62032 Camerino, Italy \\ ${ }^{3}$ Dipartimento di Scienze Geologiche, Terza Universita' di Roma, Via Ostiense 149, I-00146 Roma, Italy
}

Received October 13, 1993/Revised, accepted September 27, 1994

\begin{abstract}
Ti K-edge XANES spectra have been collected on a series of Ti-bearing silicate glasses with metasilicate and tetrasilicate compositions. The intensity of the preedge feature in these spectra has been found to change with glass composition and varies from 29 to $58 \%$ (normalized intensity) suggesting a variation in structural environent around the absorbing atom. The pre-edge peak intensity increases for the alkali titanium tetrasilicate glasses from $35 \%$ to $58 \%$ in the order $\mathrm{Li}<\mathrm{Na}<\mathrm{K}<\mathrm{Rb}$, Cs whereas for the metasilicate compositions there is a maximum for the K-bearing glass. The pre-edge peak intensity remains constant for the alkaline earth titanium metasilicate glasses, $\mathrm{Ca}$ and $\mathrm{Sr}(34 \%)$ but increases slightly for $\mathrm{Ba}(41 \%)$. As the intensity of this feature is inversely correlated with coordination number, a comparison of the pre-edge intensity data for the investigated glasses with those of materials of known coordination number leads us to establish a regression equation and to infer that the average coordination number of $\mathrm{Ti}$ in these glasses ranges from 4.8 to 5.8. Large alkali cations appear to stabilize a relatively low average coordination number for $\mathrm{Ti}$ in silicate melts. The $\mathrm{Ti}$ structural environment results appear also to vary as a function of $\mathrm{SiO}_{2}$ content within the $\mathrm{K}_{2} \mathrm{O}-\mathrm{TiO}_{2}-\mathrm{SiO}_{2}$ system.

A number of physical properties of the melts from which these glasses were quenched and of other Ti-bearing silicate melts, have been determined in recent years. Clear evidence of a variable coordination number of $\mathrm{Ti}$, consistent with the interpretation of the present XANES data is available from density measurements. These and other property determinations are compared with the present spectroscopic observations in an attempt to relate structure and properties in these melts which contain a major component with variable coordination number.
\end{abstract}

\section{Introduction}

An understanding of the relationship between properties and structure of silicate melts is the central objective

Correspondence to: D.B. Dingwell of a large body of research in the glass, materials, metallurgical and geological sciences. The incentive for spectroscopic studies of silicate melts in the geological sciences rest especially upon the promise that the understanding of silicate melt structures will allow predictions to be made about the physical and chemical behavior of silicate melts during igneous petrogenesis. Thus, it is this construction of predictive relationships between structure and properties of silicate melts that is the aim of many petrologists and mineralogists.

In the structural investigation of silicate melts, in their liquid or glassy state, a commonly used strategy for the delineation of significant trends in melt structure is to vary systematically the composition of a melt that has been chosen from a system with a relatively small number of components. This approach has been adopted in the present study. Another aspect of studies of silicate melt structure concerns the case of cations present in a range of coordination geometries which exhibit variable coordination number. Such coordination behavior is temperature-, pressure- and composition-dependent and can be described by a homogeneous equilibrium between two or more coordination geometries and involving the stabilizing cations of interest. Several cations are thought to occupy a mixture of sites with different coordination number in silicate liquids and glasses over large ranges of pressure, temperature or composition ( $\mathrm{Si}$ : Xue et al. 1989; Al: Ohtani et al. 1985; Ge: Itié et al. 1989; Fe: Virgo and Mysen 1985; B: Riebling 1967; Ti: Johnson and Carmichael 1987; Mn: Kohn et al. 1990; Ni: Galoisy and Calas 1993; Co: Keppler and Rubie 1993). In the present study we have chosen the example of Ti to illustrate how coordination number changes can influence the structure and properties of silicate melts.

The incentive for the choice of Ti was the observation that the partial molar volume of $\mathrm{Ti}$ is strongly compositionally dependent in silicate melts at high temperature (Lange and Carmichael 1990; Dingwell 1992a). Additionally, heat capacity and compressibility data appeared to show anomalous behavior which could indicate a mixed coordination number (Richet and Bottinga 
1985; Lange and Navrotsky 1993; Webb and Dingwell 1994). Considerations of these properties were also supplemented by seemingly contradictory proposals for the coordination of $\mathrm{Ti}$ in silicate melts by previous workers (see review by Mysen 1988).

In this study we present the results of an investigation of the composition-dependence of the coordination of $\mathrm{Ti}$ in glasses quenched from $1 \mathrm{~atm}$, high temperature liquids in air. In companion papers (Paris et al. 1994; Seifert et al. 1994) the effects of pressure and temperature have been investigated for selected compositions. We have employed the element-specific technique X-ray absorption near-edge structure (XANES) spectroscopy to investigate the Ti K-edge of these glasses. X-ray absorption spectroscopy has developed into a powerful technique for characterizing the environments of elements in both crystalline and amorphous compounds. Transition metals show, due to their electronic structure, a sensitive dependence of the XANES features on coordination number and site distortion. The principle spectroscopic variable is the intensity of the pre-edge feature, calibrated against mineral standards. We have correlated this feature with a shift in the average coordination number of $\mathrm{Ti}$ in our glass samples. We conclude that large alkali cations stabilize a lower coordination number of Ti in silicate melts. The effects of Ti on melt properties are discussed in light of the structural evidence.

\section{Experimental}

The starting materials for the present investigation of the coordination of $\mathrm{Ti}$ in alkali and alkaline earth titanium silicate glasses were powder mixtures of the requisite proportions of oxides and carbonates. The composition of the investigated samples was based on a tetrasilicate and a metasilicate stoichiometry plus $\mathrm{TiO}_{2}$. The general formulae are $\mathrm{X}_{2 / n}^{n+} \mathrm{TiSi}_{4} \mathrm{O}_{11}$ and $\mathrm{X}_{2 / n}^{n+} \mathrm{TiSiO}_{5}$ (where $\mathrm{X}$ is Li, $\mathrm{Na}, \mathrm{K}, \mathrm{Rb}, \mathrm{Cs}, \mathrm{Ca}, \mathrm{Sr}$, and $\mathrm{Ba}$ ) as well as an $\mathrm{Al}_{2} \mathrm{O}_{3} \cdot \mathrm{TiO}_{2} \cdot 4 \mathrm{SiO}_{2}$ composition. The melts were prepared by direct fusion of oxides and carbonates in thin walled platinum crucibles in a $\mathrm{MoSi}_{2}$ box furnace at temperatures ranging between 900 and $1650^{\circ} \mathrm{C}$. Glass samples were poured from the Pt crucibles onto a steel plate for cooling. The products of these fusions have been used for experimental determination of the density, viscosity and compressibility of the liquids at superliquidus temperatures (Dingwell 1992a, b; Webb and Dingwell 1994). Poured glass samples were stored in a dessicator until use in structure and property determinations.

The chemical compositions of the glasses have been determined by solution-based inductively coupled plasma atomic absorption spectroscopy (ICP-AES) and electron microprobe methods (Table 1). Deviations from nominal composition are minor. Under extreme conditions of low oxygen fugacity, high temperature or composition, $\mathrm{Ti}$ may occur in a partially reduced state $\left(\mathrm{Ti}^{3+}\right)$ in silicate melts (e.g., Schreiber et al. 1984). The low temperature and high oxygen fugacity of synthesis of the present samples should diminish the possibility of reduced Ti occurring in these samples. The composition and totals of the chemical analyses indicate all the $\mathrm{Ti}$ is present as $\mathrm{Ti}^{4+}$. Oxidation during the quench might however have affected the state of $\mathrm{Ti}$ in these glasses. One extra constraint is provided in situ by a weight-loss test performed at $1000^{\circ} \mathrm{C}$ for the Cs-bearing metasilicate melt. A few grams of this sample were weighed into a crucible and melted at $1000^{\circ} \mathrm{C}$ in air, suspended from a balance. No weight loss was observed. Subsequent reduction in a $\mathrm{CO}_{2}$ gas flow also failed to produce a weight loss. Had the $\mathrm{TiO}_{2}=\mathrm{Ti}_{2} \mathrm{O}_{3}+1 / 2 \mathrm{O}_{2}$ reaction been stoichiometrically sig-
Table 1. Analysed glass compositions

\begin{tabular}{lllr}
\hline $\mathrm{X}_{2} \mathrm{O}, \mathrm{XO}$ & $\mathrm{TiO}_{2}$ & $\mathrm{SiO}_{2}$ & total \\
\hline Tetrasilicate & & & \\
$7.8(\mathrm{Li})$ & 23.5 & 68.8 & 100.1 \\
$15.5(\mathrm{Na})$ & 19.5 & 63.6 & 98.6 \\
$21.6(\mathrm{~K})$ & 18.1 & 58.0 & 97.7 \\
$36.5(\mathrm{Rb})$ & 16.2 & 47.9 & 100.6 \\
$43.3(\mathrm{Cs})$ & 13.2 & 39.1 & 95.6 \\
& & & \\
Metasilicate & & & \\
$30.5(\mathrm{Na})$ & 39.6 & 29.2 & 99.3 \\
$39.9(\mathrm{~K})$ & 34.9 & 24.8 & 99.6 \\
$57(\mathrm{Rb})$ & 24.7 & 18.0 & 99.7 \\
$67(\mathrm{Cs})$ & 19.6 & 14.4 & 101.0 \\
$29.0(\mathrm{Ca})$ & 40.4 & 30.6 & 100.0 \\
$43.1(\mathrm{Sr})$ & 32.6 & 24.6 & 100.3 \\
$48.5(\mathrm{Ba})$ & 27.5 & 22.5 & 98.5 \\
\hline
\end{tabular}

Alkali-bearing glasses by ICP-AES; alkaline earth-bearing glasses by electron microprobe (see Dingwell (1992) for analytical details); metasilicate analyses reproduced from Dingwell (1992)

Table 2. Pre-edge peak $(\mathrm{P})$ intensities for reference compounds

\begin{tabular}{|c|c|c|c|c|}
\hline Sample & $N^{0}$ & C.N. & $\begin{array}{l}\text { PI } \\
(\%)^{a}\end{array}$ & Reference \\
\hline Benitoite & 1 & 6 & 6 & Waychunas (1987) \\
\hline Titanite & 2 & 6 & 16 & this work \\
\hline Anatase & 3 & 6 & 17 & this work \\
\hline Ilmenite & 4 & 6 & 18 & Waychunas (1987) \\
\hline Rutile & 5 & 6 & 21 & this work \\
\hline Neptunite & 6 & 6 & 33 & Waychunas (1987) \\
\hline Brookite & 7 & 6 & 33 & Waychunas (1987) \\
\hline Narsarsukite & 8 & 6 & 38 & this work \\
\hline Ba-fresnoite & 9 & 5 & 55 & Behrens et al. (1990) \\
\hline Sr-fresnoite & 10 & 5 & 62 & Behrens et al. (1990) \\
\hline $\mathrm{CsAlTiO}_{4}$ & 11 & 4 & $72^{b}$ & Behrens et al. (1990) \\
\hline $\mathrm{Ba}_{2} \mathrm{TiO}_{4}$ & 12 & 4 & 75 & Behrens et al. (1990) \\
\hline Ti-ricthterite & 13 & 4 & 78 & Paris et al. (1993) \\
\hline $\mathrm{Ba}_{2} \mathrm{TiO}_{4}$ & 14 & 4 & 84 & Greegor et al. (1983) \\
\hline $\mathrm{Ba}_{2} \mathrm{TiO}_{4}$ & 15 & 4 & 88 & Yarker et al. (1985) \\
\hline
\end{tabular}

a all values normalized at $5027 \mathrm{eV}$ according to Paris et al. (1993)

$\mathrm{b}$ normalized intensity evaluated by comparison with $\mathrm{n} .12$, due to the Cs L-edge interference

nificant then the weight loss in this melt, with 33 mole $\% \mathrm{TiO}_{2}$ equivalent, would have been easily measureable (cf. Fe in Dingwell $1990 \mathrm{a})$. The arguments for the alkali-bearing melts are however difficult to extend to the Li- and Al-bearing tetrasilicate melts. These exhibited a blue colour most likely arising from the presence of a trace of $\mathrm{Ti}^{3+}$. The subsequent interpretation of the spectra of these two samples reveals nothing extraordinary with respect to the rest of the sample set (see below); nevertheless however, the results for these two samples must be treated with caution.

All glass samples have been checked under the optical microscope for the possible presence of $\mathrm{TiO}_{2}$ crystalline phases and revealed to be crystal-free. The absence of crystalline material can be assessed also from the XANES spectra, since even a small amount of $\mathrm{TiO}_{2}$ crystals would be easily detected producing intense resonances in the XANES region and the features typical of rutile and anatase in the pre-edge region (Paris et al. 1993a).

The X-ray absorption spectra of powdered glass samples have been collected at the PULS X-ray line of the Frascati Synchrotron Radiation Facility (Italy). The absorption spectra were recorded 
Table 3. Characteristics of spectral features and calculated coordination number

\begin{tabular}{|c|c|c|c|c|c|}
\hline Glass & PI $(\%)$ & $\mathrm{CN}$ & $\mathrm{PE}(\mathrm{eV})$ & $\mathrm{CE}(\mathrm{eV})$ & $\mathrm{DE}(\mathrm{eV})$ \\
\hline \multicolumn{6}{|c|}{ Metasilicate composition } \\
\hline $\mathrm{Na}$ & 47 & 5.2 & 4970.9 & 4990.0 & 5003 \\
\hline $\mathrm{K}$ & 55 & 4.9 & 4971.0 & 4987 & 4999 \\
\hline $\mathrm{Rb}$ & 29 & 5.8 & 4971.6 & 4989.7 & 5003 \\
\hline $\mathrm{Cs}$ & 36 & 5.6 & 4971.2 & 4986.5 & a \\
\hline $\mathrm{Ca}$ & 34 & 5.6 & 4970.7 & 4987.3 & 4999.3 \\
\hline $\mathrm{Sr}$ & 34 & 5.6 & 4970.3 & 4986.7 & 4999.1 \\
\hline $\mathrm{Ba}$ & 41 & 5.4 & 4970.6 & 4986.9 & 4999.3 \\
\hline \multicolumn{6}{|c|}{ Tetrasilicate composition } \\
\hline $\mathrm{Li}$ & 35 & 5.6 & 4970.6 & 4987.5 & 4999.9 \\
\hline $\mathrm{Na}$ & 43 & 5.3 & 7970.3 & 4987.6 & 5000.4 \\
\hline $\mathrm{K}$ & 52 & 5.0 & 4970.2 & 4986.1 & 4998.1 \\
\hline $\mathrm{Rb}$ & 58 & 4.8 & 4970.4 & 4986.0 & 5000.0 \\
\hline $\mathrm{Cs}$ & 58 & 4.8 & 4970.2 & 4986.1 & a \\
\hline $\mathrm{A} 1$ & 43 & 5.3 & 4970.6 & 4990 & 5003.3 \\
\hline
\end{tabular}

PI normalized pre-edge peak $\mathrm{P}$ intensity; $\mathrm{CN}$ calculated average coordination number using the equation given in the text; PE peak $\mathrm{P}$ energy; $\mathrm{CE}$ peak $\mathrm{C}$ energy; $\mathrm{DE}$ peak $\mathrm{D}$ energy; ${ }^{\mathbf{a}}$ interference by Cs L-edge

at room temperature in transmission mode at the titanium $\mathrm{K}$ edge using a $\mathrm{Si}(111)$ channel-cut crystal as the monochromator. The XANES spectra have been recorded in a range of energy of $100 \mathrm{eV}$ through the absorption edge with energy steps of $0.2 \mathrm{eV}$. Resolution is $1 \mathrm{eV}$. A Ti-metal foil (EXAFS Materials, $4966.0 \mathrm{eV}$ ) was used for energy calibration and experimental reproducibility. The presence of possible changes in oxidation state was investigated by comparing the first derivative calculated for each spectrum to check for chemical shift effects. The samples have been prepared by smearing the powder obtained by grinding glass fragments in a agate mortar onto a kapton tape. Homogeneity and thickness of the samples were taken in consideration to insure a good signal/ noise ratio. Natural and synthetic Ti-bearing compounds have been used as standards, all well-characterized by X-ray diffraction methods (Table 2). Experimental data have been reduced by subtraction of the background and the spectra have been normalized to the high energy side of the spectra (at $5027 \mathrm{eV}$ ) in order to avoid the influence of multiple scattering effects. Peak intensities and half-widths have been evaluated by standard fitting method using Lorenzian curves and least-squares procedure (Table 3 ).

\section{Glasses and Melts}

It is now widely accepted in the geochemical literature that the information frozen into glasses on the structure of the corresponding liquids corresponds to the glass transition temperature for the combination of glass chemistry and quench rate (Richet and Bottinga 1986; Brandriss and Stebbins 1987; Dingwell and Webb 1990; Ihinger 1991; Keppler 1992; Mysen and Frantz 1992; Lange and Navrotsky 1993). Inasmuch as the present measurements were performed on glasses quenched from high temperature liquids we must emphasize at this time that the spectra of these glasses provide data on the structure of the silicate liquids that was quenched in at the glass transition. This range of temperature is approximately $500-600^{\circ} \mathrm{C}$ for the combination of the present compositions and experimental quench rates
(Dingwell and Webb 1990) with the consequence that considerable relaxation or backreaction of any temperature-dependent changes in melt structure could have occurred between the dwell temperatures of synthesis (above $1000^{\circ} \mathrm{C}$ ) and the glass transition temperatures. Also, as the viscosity-temperature relationships of the various compositions are not identical (Dingwell 1992b) the possibility exists that the structures are not quenched in at identical glass transition temperatures. Both of these effects can be relegated for the present melts to a minor role in influencing the comparisons of follow because in situ study of the temperature dependence of the spectra of one chosen melt composition indicates a very weak dependence of structure on temperature (Seifert et al. 1994).

\section{Results}

The XANES part of the absorption spectrum provides information on the oxidation state of the absorber and on structural details such as the coordination number of the absorbing atom and the geometry assumed by the anions (in this case, oxygens) around it but also on bond angles and distances (Brown et al. 1988).

A XANES spectrum is traditionally divided into regions, the pre-ege region where the features are determined by electronic transitions to empty bound states and the XANES region sensu stricto where the multiplescattering effects are predominant. The combined study of these effects, together with the analysis of the EXAFS oscillations, can provide a full knowledge of local geometry of the ligands around the absorber. However, the multiplicity of $\mathrm{Ti}$ environments in the types of materials under investigation suggests to focus our attention on the XANES part of the spectra, expecially considering the recent advances in the modelling of theoretical XANES spectra.

The peak located in the pre-edge region (from now on to be referred to as peak P) has been related, in transition elements, to the electronic transition $1 s-3 d$ (Waychunas 1987). This transition is forbidden when the absorber site symmetry is $O h$ (perfectly regular octahedron) whereas it becomes partially allowed when a $d-p$ orbital mixing is produced, e.g. by polyhedral distortion and consequently change of symmetry or change of coordination polyhedron. The $d-p$ mixing produces an increase of probability for the transition to occur and an increase of the peak $\mathrm{P}$ in the spectrum, whereas peak $P$ has zero intensity in a perfectly regular octahedral symmetry. The intensity of this peak is related to the electronic structure of the atom and, for transition elements, to the number of electrons in the $d$-orbitals, decreasing systematically as the $3 d$-orbitals are filled (Lytle et al. 1988) and being very high for Ti. In fact, when titanium is located in a tetrahedral site, the change in orbitals distribution and symmetry produces a considerable $d-p$ mixing giving a strong increase of the peak $\mathrm{P}$ intensity (Bianconi et al. 1985). For titanium, these evident changes in the XANES spectra as a function of the coordination number and local geometry around the 
absorber allow, therefore, one to obtain information on the geometrical environment around the absorber (Table 2). In the case of a transition element in a glass, the XANES spectrum is dominated by the resonances produced by the scattering effects of the first shell of atoms around the absorber and the absence of longrange order makes the effects due to shells farther then the first, almost negligible. On the contrary, for crystalline materials the XANES region is more complex due to the presence of resonances produced up to the fifth shell of coordination, as a function of cluster symmetry and composition (Kitzler 1993). However, even for crystalline materials, the first coordination shell mostly affects the near-edge region, as shown by multiple scattering (MS) calculations performed at the iron K-edge for pyroxenes (Paris and Tyson 1994).

The experimental Ti K-edge XANES spectra for alkali-titanium metasilicate and alkaline-earth-titanium metasilicate samples are grouped in Fig. 1 and Fig. 2 respectively. The pre-edge region is composed of a peak $\mathrm{P}$ and two small peaks (A and B) not present in all the spectra, whereas the absorption region presents two strong resonances $(C$ and $D)$ followed sometimes by a bump (E). Energy position and intensity of the XANES features are reported in Table 3. All the spectra show similar resonances in the region around the absorption edge, but they differ strongly for the intensity of the pre-edge peak (P) (Figs. 1 and 2). In fact, the peak P for metasilicate glasses increases in intensity from $\mathrm{Na}(47 \%)$ to $\mathrm{K}$ $(55 \%)$ and decreases again for the Rb sample (29\%). The spectra of the alkaline earth-bearing glasses exhibit only minor variations, the pre-edge peak being $34 \%$ for the $\mathrm{Ca}$ - and Sr-glasses but increasing to $41 \%$ for the

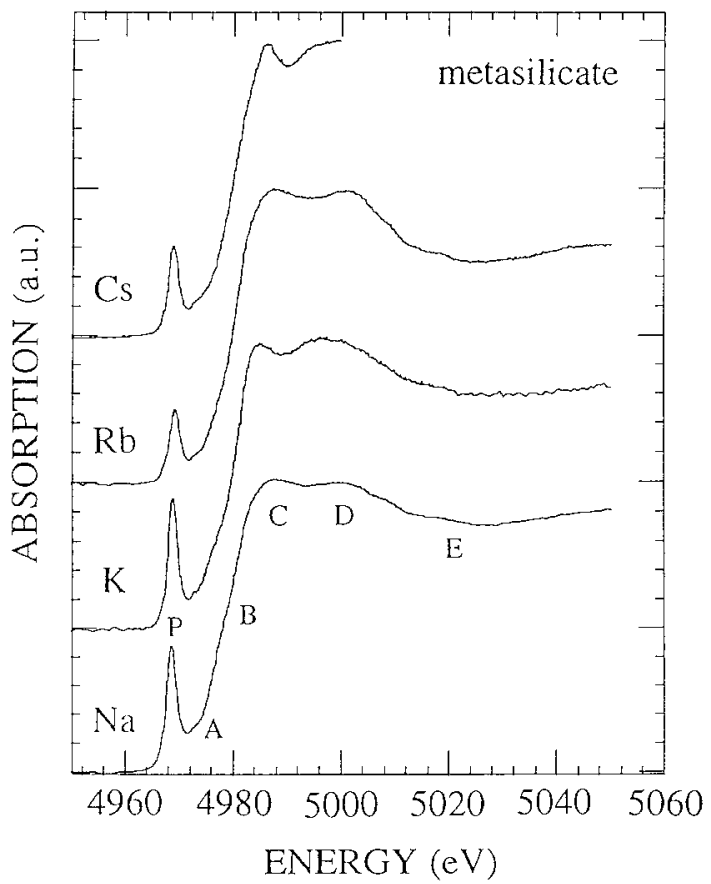

Fig. 1. Ti K-edge XANES spectra for alkali-bearing glasses of metasilicate composition. A variation of the intensity of the pre-edge peak with composition is evident. This variation is interpreted as resulting from a change in average coordination number

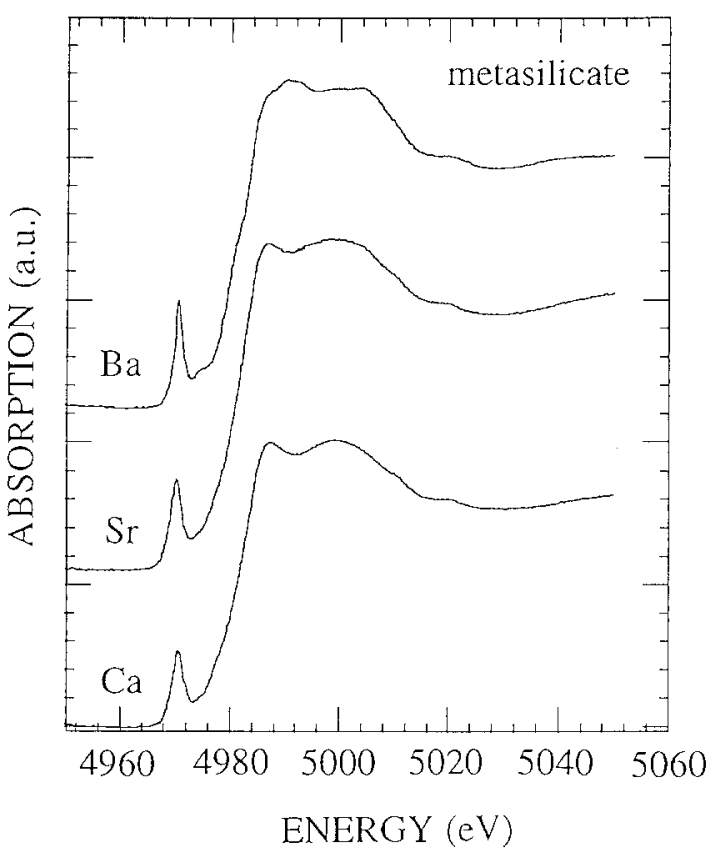

Fig. 2. Ti K-edge XANES spectra for alkaline earth-bearing glasses of metasilicate composition. The variation of the intensity of the pre-edge peak with composition is minor. The pre-edge intensity exhibited by these samples is interpreted as resulting from an average coordination number near 6 for all the glasses

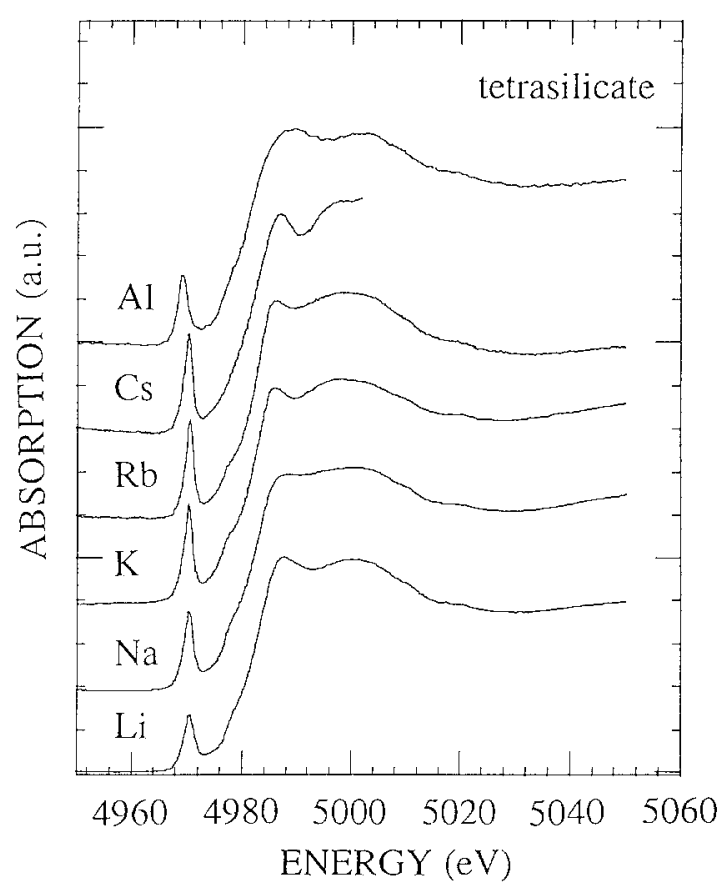

Fig. 3. Ti K-edge XANES spectra for alkali-bearing glasses of tetrasilicate composition. A variation of the intensity of the pre-edge peak with composition is evident. This variation is interpreted as resulting from a change in average coordination number. The preedge peak intensities are not the same for the tetra- and metasilicate melts, implying that the average coordination number varies with $\mathrm{SiO}_{2}$ content in the ternary alkali titanium silicate systems. Also included in this figure is the spectrum of the Al-bearing sample. This sample is discussed separately in the text 
Ba-glass. In Fig. 3 the XANES spectra of alkali-titanium tetrasilicate glasses are reported, showing that the preedge intensity increases from $35 \%$ (Li) to $58 \%$ (Cs) (Table 3 ).

Given the relationship between the pre-edge peak intensity and the local geometry around the absorber, the $P$ intensity data for all the samples have been compared with data for a series of inorganic crystalline materials (oxides, titanates and silicates). The standards were chosen between the analyzed $\mathrm{Ti}$ compounds where $\mathrm{Ti}$ is exclusively bonded to $\mathrm{O}$ (since different anions produce a different degree of covalency that modifies the $p$ character of the final state thus affecting the $\mathrm{P}$ intensity) and it is present in a variety of coordination numbers (4, 5 and 6) and geometries (regular and distorted octahedra, tetrahedron, trigonal bipyramid) (Table 2). All the samples are structurally well characterized both by XAS and XRD and, as expected, the pre-edge peak shows strong variations in intensity as a function of the coordination number (Table 2), being very high for tetrahedral coordination (72-88\%), intermediate for 5-coordination $(55-62 \%)$ and low $(0-38 \%)$ for octahedrally coordinated Ti. The uncertainty in these data can be judged from the fact that octahedral samples 2, 3 and 4 have been reported in the literature (Waychunas 1987) with the same values as those reported here, whereas the tetrahedral compound $\mathrm{Ba}_{2} \mathrm{TiO}_{4}$ is reported with a difference in values up to $13 \%$. This difference is possibly due to uncertainties concerning purity of the analyzed samples and/or to interlaboratory error. For octahedrally-coordinated titanium. the range of variation in the observed pre-edge peak intensity can be been related to polyhedral distortion, with the more intense pre-edge peak resulting from samples with less regular sites (Waychunas 1987). Not enough data are available for similar considerations of the 4- and 5-coordinated materials, due to the preference of $\mathrm{Ti}^{4+}$ for octahedral environments and the small number of crystalline compounds with different coordination numbers.

Comparison with the standards suggests that some of the alkali-bearing metasilicate glasses, which show the highest pre-edge peak heights, have lower average coordination number than the alkaline-earth-bearing metasilicate glasses, whose pre-peak heights are lower and similar to those typical of the standards containing octahedrally coordinated Ti. Figure 4 shows that by plotting the intensity data obtained for the standards versus their coordination numbers the relationship between the two parameters show a linear trend, which can be expressed by the equation IP $=-28.57 \mathrm{CN}+$ 194.9 where $\mathrm{CN}$ is the average coordination number and IP is the normalized intensity of the pre-edge peak P. The regression factor is $R=0.95$. The validity of this equation has been tested by calculating the coordination number of crystalline compounds knowing the experimental IP value. Therefore, assuming that the correlation between the coordination number and the intensity of the pre-edge peak $\mathrm{P}$ obtained for crystalline materials can be applied to glasses, we can now try to evaluate more quantitatively the average coordination number for our samples. This assumption is well supported by

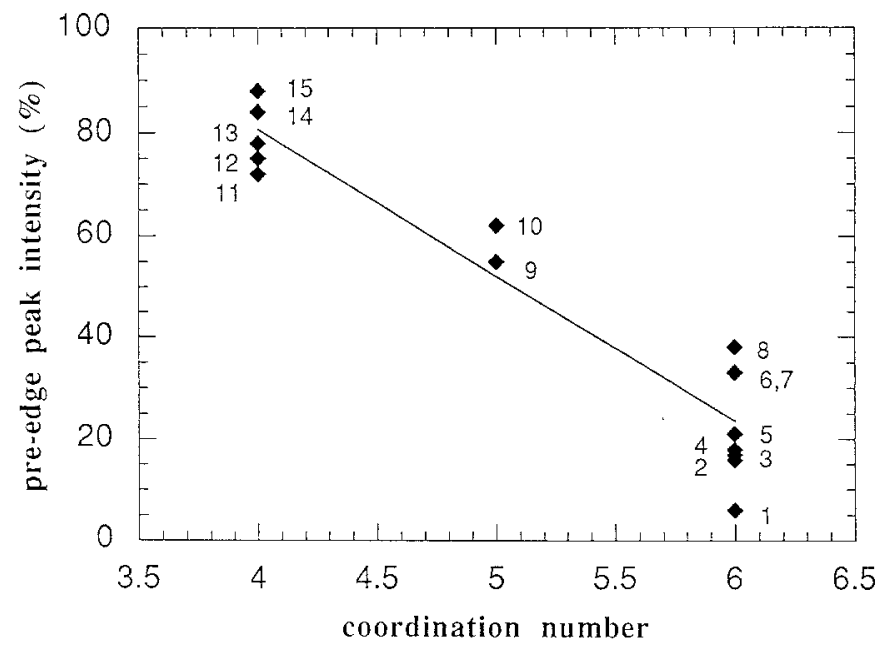

Fig. 4. The relationship between coordination number and pre-edge peak intensity for a number of crystalline reference materials. This relation is used subsequently to estimate an average coordination number for unknown samples

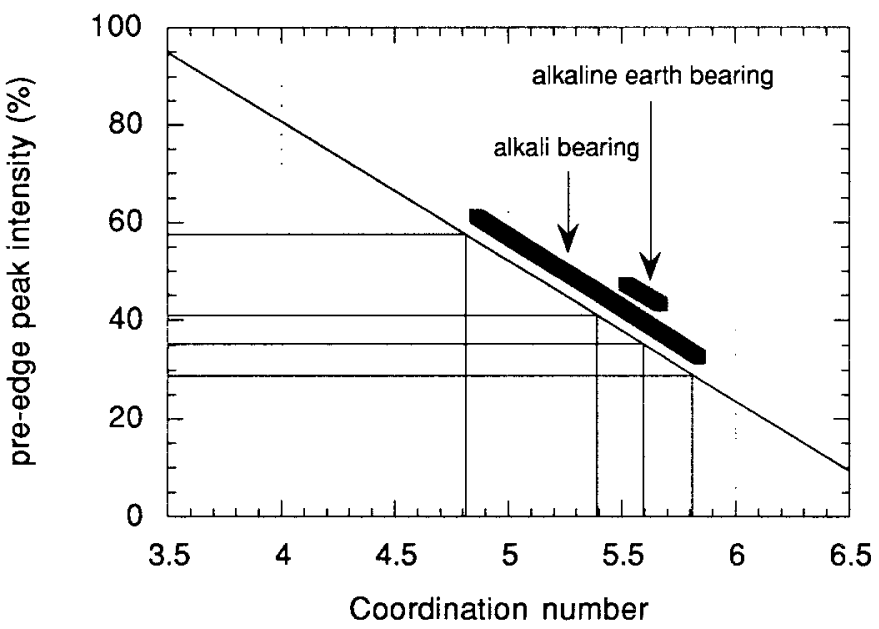

Fig. 5. The derivation of average coordination number for all of the glasses investigated in this study based on the regression presented in Fig. 4. The resultant range in average coordination number is from 4.8 to 5.8 for the alkali titanium silicate glasses and restricted to 5.4 to 5.6 for the alkaline earth silicate glasses

the comparison with the coordination number obtained by neutron diffraction on a glass of composition intermediate between our samples (Yarker et al. 1985), which has also been analyzed by XAS. The coordination number obtained for this glass is $4.82 \pm 0.02$ that is in reasonably good agreement with the value 4.7 calculated using the above equation and the experimental IP peak intensity value of $62 \%$ (renormalized for comparison with the other spectra).

The calculated coordination numbers for our glasses (Table 3) show that all the values are comprised between 4.8 and 5.8. However, in Fig. 5 we show that our data for glasses, derived from the regression given above, lie at constantly higher average coordination number for the alkaline-earth silicate glasses (5.4-5.6) and in a lower 
but larger range of $\mathrm{CN}$ for alkaline silicate glasses (4.85.8). The CN range is slightly lower for alkali tetrasilicate glasses (4.8-5.6) if compared with the metasilicate composition ones (4.9-5.8). Also, in Figs. 1 and 2 the absorption peak D of XANES experimental spectra exhibits for some samples a small shift toward higher energies, suggesting an increase of the bonding and a decrease of the mean $\mathrm{Ti}-\mathrm{O}$ bond length in passing from $\mathrm{Li}$ to $\mathrm{Cs}$ and $\mathrm{Ca}$ to Ba (Natoli and Benfatto 1986). This supports the general idea of decreasing average coordination number as a function of increased cation size in each series of glasses. Thus the XANES features appear to be particularly sensitive to the coordination of $\mathrm{Ti}$ in these glasses and this will be subsequently discussed in the interpretation of the spectra.

Further support for the application of the correlation between $\mathrm{CN}$ and $\mathrm{P}$ peak intensity to the determination of Ti local environment comes from the results obtained by MS calculations performed at the Ti $\mathrm{K}$-edge on small clusters reproducing tetravalent titanium surrounded by oxygens in different types of coordination numbers and geometries (Paris et al. 1992, 1994). The theoretical spectra obtained by using clusters of this type have been used to study of the local environment of transition elements in aqueous solutions (Garcia et al. 1986) and can be applied also to glasses, since in both cases only the contribution of the first coordination shell is expected because of the strong disorder of the more distant ligands. The MS calculations show that each geometrical environment produces characteristic features in the edge region and that the peak $P$ increases in intensity in passing from 6 to 4-fold (Paris et al. 1994). It also increases, in minor extent, for the octahedral clusters as a function of polyhedral distortion, in agreement with the trend just seen for the crystalline compounds. The variation of $\mathrm{P}$ as a function of local geometry in the theoretical spectra further supports therefore, the validity of our equation and its application to $\mathrm{CN}$ determinations. The comparison with the theoretical spectra also suggests that $\mathrm{Ti}$ is present in our glasses in three different geometries, tetrahedron, trigonal bipyramid and distorted octahedron, whose combination in the glasses is strongly composition-dependent. For example, Li-glass spectrum (Fig. 3) can be reproduced by linearly combining the distorted octahedron and the trigonal bipyramid theoretical spectra in the proportion 50:50 (Paris et al. 1994). This combination gives the exact IP value of the experimental spectrum and reproduces the other resonances (B, C and D) as well, with a $\mathrm{CN}$ value (5.5) in good agreement with that independently obtained via our equation (5.6) (Paris et al. 1994). The Li-glass spectrum is not reproduced by combining other geometries (like a tetrahedron and an octahedron) or by using other proportions. Application of this approach to the entire set of spectra need, however, to consider the contribution from tetrahedral titanium, as the other spectral features $(A, B, C, D)$ suggest that in some of these glasses it plays a more important role than in others. A more detailed investigation of Ti XANES spectra by MS calculation is in progress.

Finally, to check for the oxidation state, the energy position of the absorption edge has been measured by computing the first derivative of each spectrum. A chemical shift about $+2 \mathrm{eV}$ is generally observed in titanium compounds (Waychunas 1987) and reported as characteristic of the change in oxidation state from $\mathrm{Ti}^{3+}$ to $\mathrm{Ti}^{4+}$. This shift is evaluated in details only if a reference material is used for calibration. In this case a Ti metal foil has been measured to evaluate the energy position of the glasses spectra. The results show that there is no shift in energy between the spectra: all of them are consistent with the presence solely of $\mathrm{Ti}^{4+}$. However, the slight bluish colour of the Li- and Al-bearing samples suggest a minor presence of $\mathrm{Ti}^{3+}$ in these glasses, below the sensitivity of the XAS method, since no energy shift has been detected.

\section{Discussion}

We interpret the variations in pre-edge intensity of the XANES spectra of our Ti-bearing silicate glasses in terms of a variation in the average coordination number of $\mathrm{Ti}$ in the glass structure. The values of the calculated coordination numbers (based on the regression of Fig. 4 and presented in Fig. 5) are clearly non-integral. We interpret this observation, together with several other lines of evidence discussed below, as a consequence of a homogeneous equilibrium in these glasses between different coordination states of $\mathrm{Ti}$. Thus the coordination number quoted in Table 3 is labelled as "average coordination number". We do not intend to establish a topological stability of the fractional coordination numbers quoted here, rather they are taken to represent the average of two or more coordination states of $\mathrm{Ti}$ in these glasses, most likely 4 and 6 or 4,5 and 6 .

A further observation from the comparison of the metasilicate and tetrasilicate series of glasses can be made for the $\mathrm{Cs}, \mathrm{Rb}, \mathrm{K}$ and Na-bearing glasses. The relative intensity of the pre-edge is not the same for both compositions (Table 3 ). For the Na-bearing glasses the pre-edge decreases with increasing $\mathrm{SiO}_{2}$ content whereas for the $\mathrm{K}$-bearing glasses it is almost constant and for the $\mathrm{Rb}$ - and Cs-bearing glasses it decreases strongly with decreasing $\mathrm{SiO}_{2}$. Variation of the relative intensity of the pre-edge in the $\mathrm{TiO}_{2}-\mathrm{SiO}_{2}$ system has also been observed by Greegor et al. (1983). They observed an initial increase in the pre-edge intensity with the addition of $\mathrm{TiO}_{2}$ to $\mathrm{SiO}_{2}$ up to $2 \mathrm{wt} . \%$ a constant pre-edge intensity up to the addition of $7.5 \mathrm{wt} . \%$, and then a subsequent decrease in the pre-edge intensity with further addition of $\mathrm{TiO}_{2}$ beyond this to $14.7 \mathrm{wt} . \%$. According to our preferred interpretation, these trends reflect differences in the average coordination number with melt composition. In fact such trends must exist if the equilibrium between the Ti coordination species is a homogeneous one involving other melt components. The relative pre-edge intensity data presented here for the alkali meta-versus alkali tetrasilicate compositions can been interpreted as extensions of the trends observed by Greegor et al. (1983) into the respective alkali-bearing ternary systems. According to the forgoing discussion 
our observation of similar pre-edge intensities for the $\mathrm{K}$ metasilicate and tetrasilicate compositions must be fortuitous in that the pre-edge is predicted to be in general composition dependent within the ternary. Support for this comes from data reported by Yarker et al. (1986) on a glass composition intermediate between our two compositions, $\mathrm{K}_{2} \mathrm{TiSi}_{2} \mathrm{O}_{7}$. The pre-edge intensity reported for this composition yields an average coordination number of 4.7 from our regression, in good agreement with the value $4.82 \pm 0.2$ reported by Yarker et al. (1986) from their combined neutron diffraction and XAS study. Interestingly, the pre-edge intensity of their glass is much higher than our data for the tetra- and metasilicate compositions and thus supports the notion that a maximum in pre-edge intensity (and by inference a minimum in average coordination number) occurs as a function of composition within the $\mathrm{K}_{2} \mathrm{O}-\mathrm{TiO}_{2}-$ $\mathrm{SiO}_{2}$, just as is seen for the $\mathrm{TiO}_{2}-\mathrm{SiO}_{2}$ binary. We know that the stability of the low coordinate, high preedge species is alkali specific and thus the stability as a function of $\mathrm{SiO}_{2}$ content can be individual as well. We would only add that according to this interpretation the pre-edge intensity in all ternary alkali-bearing systems must eventually decrease as the pure $\mathrm{TiO}_{2}$ component is approached.

What evidence can we assemble to independently support this proposed homogeneous equilibrium between coordination states of Ti? There are three lines of evidence. Firstly, the value of the pre-edge intensity, in addition to being a function of composition (both $\mathrm{SiO}_{2}$ content and alkali identity), is also a smooth continuous function of pressure (Paris et al. 1994) and possibly temperature (Seifert et al. 1994). The continuous composition-, temperature- and pressure-dependence of the preedge intensity is the type of behavior expected for a homogeneous equilibrium with finite values of enthalpy and volume, the latter of which results in the pressuredependence observed by Paris et al. (1994). Were the non-integral value of coordination number an actual coordination state of constant composition and structure rather than an equilibrium between coordination numbers then the temperature- and pressure-dependence of the transition to another coordination state might be expected to occur at some elevated and discrete pressure and temperature. We propose that the continuous composition-, pressure- and temperature-dependence of the pre-edge intensity results from the subequal proportions of differing coordination polyhedra that are implied by the non-integral average coordination numbers obtained in this study. Finally with regard to this point, the pressure-dependence of the proposed equilibrium is in the direction favouring higher coordination. Although the entropic consequences of a putative coordination shift from 4 to 6 coordination are ambiguous, the volume consequences are clear. The shift in coordination from 4 to 6 should result in a volume reduction per oxygen atom. This is consistent with the observed pressure-induced shift of Ti to lower pre-edge intensity and independently consistent with volume measurements described next.

The second type of evidence favouring the interpreta- tion of speciation proposed above lies in the available property data for melts of the metasilicate composition. Specifically, the density of melts of the titanium metasilicate composition have been determined and the partial molar volume of the $\mathrm{TiO}_{2}$ component has been calculated for each using the available densities of the respective Ti-free metasilicate melts from sources in the literature. The partial molar volume of $\mathrm{TiO}_{2}$ (est. at $1000^{\circ} \mathrm{C}$ ), so calculated rises from a value of 23.9(5) in the $\mathrm{CaTiSiO}_{5}$ melt to a value of $28.5(5)$ in the $\mathrm{K}_{2} \mathrm{TiSiO}_{5}$ composition. The results of these density determinations have been interpreted as a change in the coordination of Ti from a relatively low-volume polyhedron in the alkaline earthbearing melts to an increasingly large-volume polyhedron or combination of polyhedra in certain alkali-bearing melts. This interpretation is consistent with the current interpretation of the pre-edge intensity data of the present study.

Further property data also point to an anomalous behavior of the $\mathrm{TiO}_{2}$ component in the temperature dependent properties of equilibrium Ti-bearing silicate liquids. Richet and Bottinga (1985) have demonstrated that portion of the heat capacity of silicate melts contributed by temperature-dependent configurational changes, the so-called "configurational heat capacity", which is derived by subtracting the glassy value of the heat capacity from the measured value above the glass transition, is anomalously large and temperature-dependent for titanium-bearing alkali silicate melts in comparison with Tifree alkali silicates. The anomalously large configurational heat capacity observed above the glass transition can be attributed to a temperature-dependent reaction involving the coordination of $\mathrm{Ti}$ in the Ti-bearing melts. Similarly, Lange and Navrotsky (1993) have emphasized that the temperature-dependence of the configurational entropy of alkali titanosilicate liquids is anomalously large at temperatures just above the glass transition but becomes similar to that of Ti-free alkali silicate melts at temperatures of approximately $1000^{\circ} \mathrm{C}$. The observation that the anomalous configurational heat capacity disappears at high temperature might indicate that the reaction reaches completion at high temperature. The data for the temperature dependent shift of the pre-edge intensity for a Rb-titanosilicate melt presented by us (Seifert et al. 1994) can be interpreted to indicate a subtle temperature-dependent coordination shift of $\mathrm{Ti}$ which is complete at such high temperatures.

Property data constraining the coordination number of $\mathrm{Ti}$ also come from recent ultrasonic determinations of the bulk modulus of alkali and alkaline earth titanium silicate liquids of the metasilicate composition (Webb and Dingwell 1994). Preliminary data from these melts indicate that the compressibility of the partial molar volume of $\mathrm{TiO}_{2}$ component is strongly dependent on composition. This is an anticipated consequence of varying the proportions of two or more coordination states of $\mathrm{Ti}$ in silicate liquids as a function of composition. The $\mathrm{K}$ and $\mathrm{Na}$ titanium metasilicate melts, in particular, show a large decrease in bulk modulus compared with the equivalent alkali disilicate compositions (related by the exchange operator $\mathrm{TiSi}_{-1}$ ). This sensitivity for the 
$\mathrm{K}$ and Na-bearing melts is tentatively interpreted as resulting from the subequal proportions of differing coordination states of $\mathrm{Ti}$ in those melts. Further, the pressure-dependence of the pre-edge intensity (Paris et al. 1994) implies that a coordination shift is occurring with pressure and the variable compressibility of the $1 \mathrm{~atm}$ liquids is consistent with this observation.

The third line of evidence consistent with the interpretation of variable pre-edge intensity as a consequence of changes in the average (non-integral) coordination number of $\mathrm{Ti}$ in the silicate melts comes from analogous interpretations of other types of spectroscopic data for Ti and for other cations in silicate melts. Previous studies of the coordination of $\mathrm{Ti}$ in silicate glasses have been undertaken in a variety of chemical systems and using a number of different spectroscopic techniques (e.g. neutron scattering: Wright et al. 1977; vibrational spectroscopy: Takahashi et al. 1977; Furukawa and White 1979; Mysen et al. 1980; Kusabiraki 1986; X-ray absorption spectroscopy: Greegor et al. 1983; Sandstrom et al. 1980; Yarker et al. 1986). Previous spectroscopic studies of the structural role of $\mathrm{Ti}$ in silicate glasses have been interpreted as evidence for a composition-dependence of the coordination number of $\mathrm{Ti}$ and for the presence of both 4 and 6-fold coordinated of $\mathrm{Ti}$ in certain compositions. Of special interest in the present context are the studies of Wright et al. (1977), Hanada and Soga (1980) and Yarker et al. (1987). Wright et al. (1977) conducted a neutron scattering study of $\mathrm{K}_{2} \mathrm{Si}_{2} \mathrm{TiO}_{7}$ glass, obtaining an average bond length of $1.95 \AA$. They concluded that the average coordination number of $\mathrm{Ti}$ in this composition is 5.2. Hanada and Soga (1980) conducted a study of the chemical shift of the Ti $\mathrm{K} \beta$ X-ray emission spectrum for glasses in the $\mathrm{Na}_{2} \mathrm{O}-\mathrm{TiO}_{2}-\mathrm{SiO}_{2}$ system. They observed a composition-dependence of the wavelength which they interpreted as an increasing proportion of tetrahedrally-coordinated $\mathrm{Ti}$ with increasing Ti content to $33 \mathrm{~mol} \% \mathrm{TiO}_{2}$ and a subsequent decrease. Their Fig. 1 indicates an average coordination number near 5.2. Finally, as noted above, Yarker et al. (1987) have interpreted their neutron diffraction and XAS data in terms of a non-integral coordination number of 4.8 .

Previous discussions of the structural role of $\mathrm{TiO}_{2}$ in silicate melts have returned again and again to the distinction between two possibilities. Firstly, that the anomalous coordination of $\mathrm{Ti}$ in large-alkali silicate glasses is due to an extreme distortion of an octahedral coordination and secondly that the anomalous coordination results from a proportion of lower coordination species. What distinguishes these two possibilities has to do with the definition of a coordination number for $\mathrm{Ti}$ in these melts. In our studies we have observed 1) a partial molar volume which varies up to $20 \%$ with composition and 2) a pre-edge feature in the XANES spectra which varies, over a range of average coordination number from 4.8 to 5.8 . We find these data easiest to reconcile with the interpretation of a changing average coordination number of $\mathrm{Ti}$ in these melts. We have chosen to describe this structural degree of freedom as a homogeneous reaction between lower and higher coordinate species, dependent on composition, temperature and pressure. These species may be greatly distorted and the definition of a coordination number may be blurred. Thus whether one chooses to interpret the pressure-, temperature- and compositional features of these spectra as a reaction between coordination polyhedra of regular geometry or between species of varying degree of distortion of an octahedron, one must explain the large molar volume difference between the species. This term is large enough to lead us to conclude that the best description of the homogeneous equilibrium occurring in these melts yields an effective shift in the coordination number of $\mathrm{TiO}_{2}$.

\section{Conclusion}

The coordination of $\mathrm{Ti}$ in simple ternary silicate melts can be described by a composition-dependent average coordination number between 4 and 6 . The presence of large alkali cations reduces the proportion of high coordinate Ti species, presumably by shifting a homogeneous equilibrium involving variously coordinated $\mathrm{Ti}$ species. The variation in the average coordination number of $\mathrm{T} i$ is reflected in a composition-dependence of physical properties such as density, heat capacity and compressibility. The equilibrium appears to be pressureand temperature-dependent as well. Average non-integral coordination of cations in silicate melts may well be the rule rather than the exception.

Acknowledgements. We thank Anna Dietel for ICP-AES analyses and Detlef Krauße for microprobe analysis. We thank E. Burattini and S. Mobilio for use of PWA and PULS facilities. This work has been supported by MURST and CNR Grant-in-aid CT91 0815.CT05, the Vigoni exchange Program of the Conferenza dei Rettori delle Universitá Italiane (CRUI - Italy) and the Deutsche Akademische Austauschdienst (DAAD - Germany) and Fonds der Chemischen Industrie, Frankfurt.

\section{References}

Behrens P, ABmann S, Felsche J, Vetter S, Schulz-Ekloff G, Jaeger NI, Niemann W (1990) Metal-atom substituted microporous materials - X-ray absorption spectroscopic studies. Proc VIth Int Conf X-ray Absorption Fine Structure York

Brandriss ME, Stebbins JF (1988) Effects of temperature on the structures of silicate liquids: ${ }^{29} \mathrm{Si} \mathrm{NMR}$ results. Geochim Cosmochim Acta 52:2659-2669

Brown GE, Calas G, Waychunas GA, Petiau J (1988) X-ray absorption spectroscopy and its applications in mineralogy and geochemistry. In: Hawthorne F (ed) Spectroscopic methods in mineralogy. Reviews in mineralogy, MSA, 18:431-512

Davoli I, Paris E, Mottana A, Marcelli A (1987) XANES analysis on pyroxenes with different $\mathrm{Ca}$ concentration in M2 site. Phys Chem Minerals 14:21--24

Dingwell DB (1990) Experimental determination of some physical properties of iron-bearing silicate melts. Glastech Ber 63K :289297

Dingwell DB (1992a) Density of some titanium-bearing silicate liquids and the compositional dependence of the partial molar volume of $\mathrm{TiO}_{2}$. Geochim Cosmochim Acta 56:3403-3407

Dingwell DB (1992b) Shear viscosity of alkali and alkaline earth titanium silicate liquids. Amer Mineral 77:270-274

Dingwell DB, Webb SL (1990) Relaxation in silicate melts. Eur J Mineral 2:427-449 
Furukawa T, White WB (1979) Structure and crystallization of glasses in the $\mathrm{Li}_{2} \mathrm{Si}_{2} \mathrm{O}_{5}-\mathrm{TiO}_{2}$ system determined by Raman spectroscopy. Phys Chem Glass 20:69-80

Galoisy L, Calas G (1993) Structural environment of nickel in silicate glass/melt systems: Part 1. Spectroscopic determination of coordination states. Geochim Cosmochim Acta 57:36133626

Garcia J, Bianconi A, Benfatto M, Natoli CR (1986) Coordination geometry of transition metal ions in dilute solutions by XANES. J Physique 47, C8:49-54

Greegor RB, Lytle WB, Sandstrom DR, Wong J, Schultz P (1983) Investigation of $\mathrm{TiO}_{2}-\mathrm{SiO}_{2}$ glasses by $\mathrm{X}$-ray absorption spectroscopy. J Non-Cryst Sol 55:27-43

Hanada T, Soga N (1980) Coordination of titanium in sodium titanium silicate glasses. J Non-Cryst Sol 38 \& 39:105-110

Ihinger P (1991) Experimental investigations of water in silicate glasses. Thesis Caltech.

Itie' JP, Polian A, Calas G, Petiau J, Fontaine A, Tolentino H (1989) Pressure-induced coordination changes in crystalline and vitreous $\mathrm{GeO}_{2}$. Phys Rev Lett 63:398-401

Johnson T, Carmichael ISE (1987) The partial molar volume of $\mathrm{TiO}_{2}$ in multicomponent silicate melts. Geol Soc Amer Abstr Prog 19:719

Keppler H (1992) Crystal field spectra and geochemistry of transition metal ions in silicate melts and glasses. Amer Mineral $77: 62-84$

Keppler H, Rubie D (1993) Pressure-induced coordination changes of transition-metal ions in silicate melts. Nature 364:54-56

Kitzler P (1992) X-ray absorption near-edge structure spectra for bulk materials; multiple scattering analysis versus a phenomenological approach. Phys Rev B 46:17 10540-10546

Kohn S, Charnock JM, Henderson CMB, Greaves GN (1990) The structural environments of trace elements in dry and hydrous silicate glasses; a manganese and strontium K-edge X-ray absorption spectroscopic study. Contrib Mineral Petrol 105:359368

Kusabiraki K (1986) Infrared spectra of vitreous silica and sodium silicates containing titanium. J Non-Cryst Sol 79:208--212

Lange RA, Carmichael ISE (1990) Thermodynamic properties of silicate liquids with emphasis on density, thermal expansion and compressibility. Rev Mineral 24:25-64

Lange RA, Navrotsky A (1993) Heat capacities of $\mathrm{TiO}_{2}$-bearing liquids: evidence for anomalous changes in configurational entropy with temperature. Geochim Cosmochim Acta 57:30013011

Lytle FW, Greegor RB, Panson AJ (1988) Discussion of X-ray absorption near edge structure: application to $\mathrm{Cu}$ in high $T_{c}$ superconductors, $\mathrm{La}_{1.8} \mathrm{Sr}_{0.2} \mathrm{CuO}_{4}$ and $\mathrm{YBa}_{2} \mathrm{Cu}_{3} \mathrm{O}_{7}$. Phys Rev B37: 1550-1562

Mysen BO (1988) Structure and Properties of Silicate Melts. Elsevier, pp. 354

Mysen BO, Frantz J (1992) Raman spectroscopy of silicate melts at magmatic temperatures: $\mathrm{Na}_{2} \mathrm{O}-\mathrm{SiO}_{2}, \mathrm{~K}_{2} \mathrm{O}-\mathrm{SiO}_{2}$, and $\mathrm{Li}_{2} \mathrm{O}-\mathrm{SiO}_{2}$ binary compositions in the temperature range 25$1475^{\circ} \mathrm{C}$. Chem Geol 96:321-332

Mysen BO, Ryerson FJ, Virgo D (1980) The influence of $\mathrm{TiO}_{2}$ on structure and derivative properties of silicate melts. Amer Mineral 65:867-884

Natoli R, Benfatto M (1986) A unifying scheme of interpretation of X-ray absorption spectra based on multiple scattering theroy. J Phys 47 C8:11-23
Ohtani E, Taulelle F, Angell CA (1985) $\mathrm{Al}^{3+}$ coordination changes in liquid silicates under pressure. Nature 314:78-81

Paris E, Romano C, Benfatto M (1992) Multiple scattering calculations and XANES data on titanium environment in minerals and glasses. Terra Abstracts 4:34

Paris E, Mottana A, Della Ventura G, Robert JR (1993) Ti valence and coordination in synthetic amphiboles of the richterite/Tirichterite series. A synchrotron radiation XAS study. Eur J Mineral 5:455-464

Paris E, Tyson TA (1994) Iron site geometry in orthopyroxene: multiple scattering calculations and XANES study. Phys Chem Minerals (in press)

Paris E, Dingwell DB, Seifert FA, Mottana A, Romano C (1994) Pressure-induced coordination change of $\mathrm{Ti}$ in silicate glass: a XANES study. Phys Chem Mineral 21:510-515

Paris E, Romano C, Wu Z (1994) Application of multiple scattering calculations to the study of local geometry in silicate glasses of geological interest. XAFS VIII Conf Proc Berlin 1994

Richet P, Bottinga Y (1985) Heat capacity of aluminum-free liquid silicates. Geochim Cosmochim Acta 49:471-486

Richet P, Bottinga Y (1986) Thermophysical properties of silicate glasses and liquids. Rev Geophys 24:1-25

Riebling EF (1967) Volume relations in $\mathrm{Na}_{2} \mathrm{O}-\mathrm{B}_{2} \mathrm{O}_{3}$ and $\mathrm{Na}_{2} \mathrm{O}$. $\mathrm{SiO}_{2} \cdot \mathrm{B}_{2} \mathrm{O}_{3}$ melts at $1300^{\circ} \mathrm{C}$. J Am Cer Soc 50:46-53

Sandstrom DR, Lytle FW, Wei P, Greegor RB, Wong J, Schultz $\mathrm{P}$ (1980) Coordination of $\mathrm{Ti}$ in $\mathrm{TiO}_{2}-\mathrm{SiO}_{2}$ glasses by X-ray absorption spectroscopy. J Non-Cryst Sol 41:201-207

Schreiber HD, Balazs GB, Carpenter BE, Kirkley JE, Minnix LM, Jamison PL (1984) An electromotive force series in a borosilicate glass-forming melt. J Am Cer Soc 67:C-106-108

Seifert F, Paris E, Dingwell DB, Mottana A, Romano C, Davoli I (1994) In situ high temperature study of Ti coordination in a Rb-silicate glass and liquid to $1400^{\circ} \mathrm{C}$ (submitted to Glastech Ber)

Takahashi K, Mochida N, Yoshida Y (1977) Properties and structure of silicate glasses containing tetravalent cations. J Cer Soc Jap $85: 330-340$

Virgo D, Mysen BO (1985) The structural state of iron in oxidized versus reduced glasses at $1 \mathrm{~atm}$ : a ${ }^{57} \mathrm{Fe}$ Mössbauer study. Phys Chem Mineral 12:65-76

Waychunas GA (1987) Synchrotron radiation XANES spectroscopy of $\mathrm{Ti}$ in minerals: effects of $\mathrm{Ti}$ bonding distances, $\mathrm{Ti}$ valence, and site geometry on absorption edge structure. Amer Mineral 72:89-101

Waychunas GA, Brown GE Jr, Ponader CW, Jackson WE (1988) Evidence from X-ray absorption for network-forming $\mathrm{Fe}^{2+}$ in molten alkali silicates. Nature 332:251-253

Webb SL, Dingwell DB (1994) Compressibility of $\mathrm{TiO}_{2}$-bearing alkali silicate melts. (in press - Contrib Mineral Petrol)

Wright AC, Yarker CA, Johnson PAV, Wedgwood FA (1977) Neutron scattering techniques for structural studies of amorphous solids. In: Frischat GH (ed) Non Crystalline Solids, TransTech, pp 118-123

Xue X, Stebbins JF, Kanzaki M, Tronnes RG (1989) Silicon coordination and speciation changes in a silicate liquid at high pressures. Science 245:962-964

Yarker CA, Johnson PAV, Wright AC (1986) Neutron diffraction and EXAFS evidence for $\mathrm{TiO}_{5}$ units in vitreous $\mathrm{K}_{2} \mathrm{O} \cdot \mathrm{TiO}_{2}$. $2 \mathrm{SiO}_{2}$. J Non-Cryst Sol 79:117-136 